\title{
Race- and Isolate-specific Molecular Marker Development through Genome- Realignment Enables Detection of Korean Plasmodiophora brassicae Isolates, Causal agents of Clubroot Disease
}

\author{
Ji -Yun Jeong ${ }^{1 \dagger}$, Arif Hasan Khan Robin ${ }^{1,2 \dagger}$, Sathishkumar Natarajan ${ }^{1 \dagger}$, Rawnak Laila ${ }^{1}$, Hoy-Taek Kim ${ }^{1}$, \\ Jong-In Park ${ }^{1 *}$, and IIl-Sup Nou ${ }^{1 *}$ \\ ${ }^{I}$ Department of Horticulture, Sunchon National University, Suncheon 57922, Korea \\ ${ }^{2}$ Department of Genetics and Plant Breeding, Bangladesh Agricultural University, Mymensingh-2202, Bangladesh
}

(Received on December 20, 2017; Revised on August 26, 2018; Accepted on August 30, 2018)

Clubroot is one of the most economically important diseases of the Brassicaceae family. Clubroot disease is caused by the obligate parasite Plasmodiophora brassicae, which is difficult to study because it is nonculturable in the laboratory and its races are genetically variable worldwide. In Korea, there are at least five races that belongs to four pathotype groups. A recent study conducted in Korea attempted to develop molecular markers based on ribosomal DNA polymorphism to detect $P$. brassicae isolates, but none of those markers was either race-specific or pathotype-specific. Our current study aimed to develop race- and isolate-specific markers by exploiting genomic sequence variations. A total of 119 markers were developed based on unique variation exists in genomic sequences of each of the races. Only 12 markers were able to detect $P$. brassicae strains of each isolate or race. Ycheon14 markers was specific to isolates of race 2, Yeoncheon and Hoengseong. Ycheon9 and Ycheon10 markers were specific to Yeoncheon isolate (race 2, pathotype 3), ZJ1-3, ZJ14 and ZJ1-5 markers were specific to Haenam2 (race

\footnotetext{
${ }^{\dagger}$ These authors contributed equally to this work as first authors.

*Corresponding author.

Jong-In Park

Phone) +82-61-750-3241, FAX) +82-61-750-3208

E-mail)jipark@sunchon.ac.kr

Ill-Sup Nou

Phone) +82-61-750-3249, FAX) +82-61-750-3208

E-mail)nis@sunchon.ac.kr

(c) This is an Open Access article distributed under the terms of the Creative Commons Attribution Non-Commercial License (http:// creativecommons.org/licenses/by-nc/4.0) which permits unrestricted noncommercial use, distribution, and reproduction in any medium, provided the original work is properly cited.
}

Articles can be freely viewed online at www.ppjonline.org.
4) isolate, ZJ1-35, ZJ1-40, ZJ1-41 and ZJ1-49 markers were specific to Hoengseong isolate and ZJ1-56 and ZJ1-64 markers were specific to Pyeongchang isolate (race 4, pathotype 3). The PCR-based sequence characterized amplified region (SCAR) markers developed in this study are able to detect five Korean isolates of $P$. brassicae. These markers can be utilized in identifying four Korean $\boldsymbol{P}$. brassicae isolates from different regions. Additional effort is required to develop race- and isolate-specific markers for the remaining Korean isolates.

Keywords : clubroot, isolate-specific markers, Plasmodiophora bassicae, SCAR markers, sequence comparison

Handling Associate Editor : Seo, Young-Su

Clubroot is a serious disease of the Brassicaceae that is increasingly problematic worldwide (Wang et al., 2008). This disease is caused by the soil-borne biotrophic cercozoan Plasmodiophora brassicae Woronin (Nikolaev et al., 2004). This pathogen lives in soil for up to 20 years as resting spores (Karling, 1968; Wallenhammar, 1996) that are difficult to control with anti-microbial chemicals or crop rotation (Tsushima, 2000; Voorrips, 1995). Root hairs are the primary target of this pathogen, but the infection eventually spreads to the cortical region of the roots. The infected roots swell to form of galls or clubs that severely reduce the quality and production of Brassica crops, such as cabbage (Dixon, 2009; Kim et al., 2009). Several factors increase the likelihood of $P$. brassicae infection, including acidification of soils, changes in climate that favor the growth of this pathogen, an increase in cultivated area devoted to Brassica crops, and transportation of crucifer- 
ous crop products and residues (Li et al., 2013). The resting spores multiply exponentially in the newly infected soil if they parasitize a cruciferous crop.

Understanding of clubroot disease has been limited by several aspects of the pathogen's biology. P. brassicae is non-culturable in laboratory conditions and is difficult to clone and sequence due to its high genomic similarity with host plants (Bryngelsson et al., 1988; Laila et al., 2017; Schwelm et al., 2015). Moreover, several pathotypes (a group of organisms that have the same pathogenicity on a specified host) and races of $P$. brassicae exist worldwide (Buczacki et al., 1975; Hatakeyama et al., 2004; Kuginuki et al., 1999; Somé et al., 1996; Williams, 1966). Kim et al. (2016) re-classified Korean P. brassicae isolates into four pathotypes (Jo et al., 2011; Kim et al., 2016). Development of race-specific markers would enable more effective and precise detection of this pathogen. Such molecular markers have been used effectively in plant disease diagnostics for many years, including limited methods in P. brassicae based on PCR amplification of DNA from galls or resting spores (Faggian and Strelkov, 2009; Ito et al., 1997, 2008; Li et al., 2017; Wallenhammar and Arwidsson, 2001; Yang et al., 2002). Ito et al. (1997) cloned and sequenced $1.4 \mathrm{~kb}$ DNA fragment from 19 different Japanese P. brassicae isolates and found that the markers covering that sequence do not amplify fungi and bacterial DNA they studied. Thus, the authors suggested two markers PBTZS-3 and PBTZS-4 for detecting $19 \mathrm{P}$. brassicae isolates. This research group also developed a single-tube nested polymerase chain reaction method for detecting $P$. brassicae isolates from soil samples. In another study conducted in Sweden, Wallenhammar and Arwidsson (2001) found two markers of $389 \mathrm{bp}$ and $507 \mathrm{bp}$ were able to detect $P$. brassicae isolates from soil sample of both Sweden and UK by a nested PCR method. The authors, however, found that isolates from two different countries had variation in 18s and ITS1 (intertranscribed spacer 1) regions indicating that those markers are unable to differentiate any isolate specific variations. In a recent study in China, Li et al. (2017) successfully detected an unknown $P$. brassicae isolate after targeting D85819 and Prol gene-specific primers. However, none of those PCR based methods could distinguish between the different $P$. brassicae isolates. $P$. brassicae isolates in Korea differ in their level of pathogenicity and virulence (Laila, 2018). It might be also possible that two or more isolates of from adjacent geographical regions might co-exist in a particular location. Furthermore, isolates from one region may translocate to another region due to transportations of green plant products. Therefore, an effective detection protocol of existing Korean isolates is important for their race-specific and isolate-specific identity. Laila et al. (2017) attempted to distinguish 11 Korean $P$. brassicae isolates by creating ribosomal DNA (rDNA) markers. This approach produced four high resolution melting-based markers targeting smaller subunit region of ribosomal DNA that can detect two groups of the 11 P. brassicae isolates. However, none of these markers could distinguish between the Korean isolates. In this study, we compared all available genomic sequences of $P$. brassicae to obtain isolate-specific molecular markers.

\section{Materials and Methods}

Retrieval and alignment of $\boldsymbol{P}$. brassicae genomic DNA sequences. Genomic sequences of $P$. brassicae isolates e3 and ZJ-1 were retrieved from NCBI (Genbank accession numbers GCA_001049375.1 and GCA_002093825.1, respectively). The sizes of the $\mathrm{e} 3$ and $\mathrm{ZJ}-1$ genomes were 24.0508 and $24.8311 \mathrm{Mb}$, respectively (Table 1). We recently sequenced partial genomic DNA sequences of four additional $P$. brassicae isolates (21 Mb each): Daejeon, Gangneung 1, Haenam-2, and Yeoncheon (SRA accession: SRP150814). Genomic sequences of these four isolates were compared to identify variable nucleotide positions. These six sequences were aligned using the "Align with progressiveMauve" approach in Mauve (v. 2.4.0) (Darling et al., 2010) and visualized in Geneious (v. 11.0.3, Kearse et al., 2012). This comparison identified variable regions

Table 1. Plasmodiophora brassicae isolates used for comparing genome sequences. Sequences of e3 and ZJ-1 isolates were compared to four Korean isolates

\begin{tabular}{cccccc}
\hline Isolate & Sequence & Race & Country & Genome size & Reference \\
\hline e3 & Genome & Race unknown & Sweden & $24.0508 \mathrm{Mb}$ & Schwelm et al. (2015) \\
ZJ-1 & Genome & Race 1 & China & $24.8311 \mathrm{Mb}$ & Bi et al. (2016) \\
Daejeon & Whole genome re-seq & Race 5 & Korea & $21 \mathrm{Mb}$ & \\
Gangneung 1 & Whole genome re-seq & Race 9 & Korea & $21 \mathrm{Mb}$ & SRA accession: SRP150814 \\
Haenam-2 & Whole genome re-seq & Race 4 & Korea & $21 \mathrm{Mb}$ & $21 \mathrm{Mb}$ \\
Yeoncheon & Whole genome re-seq & Race 2 & Korea & & \\
\hline
\end{tabular}




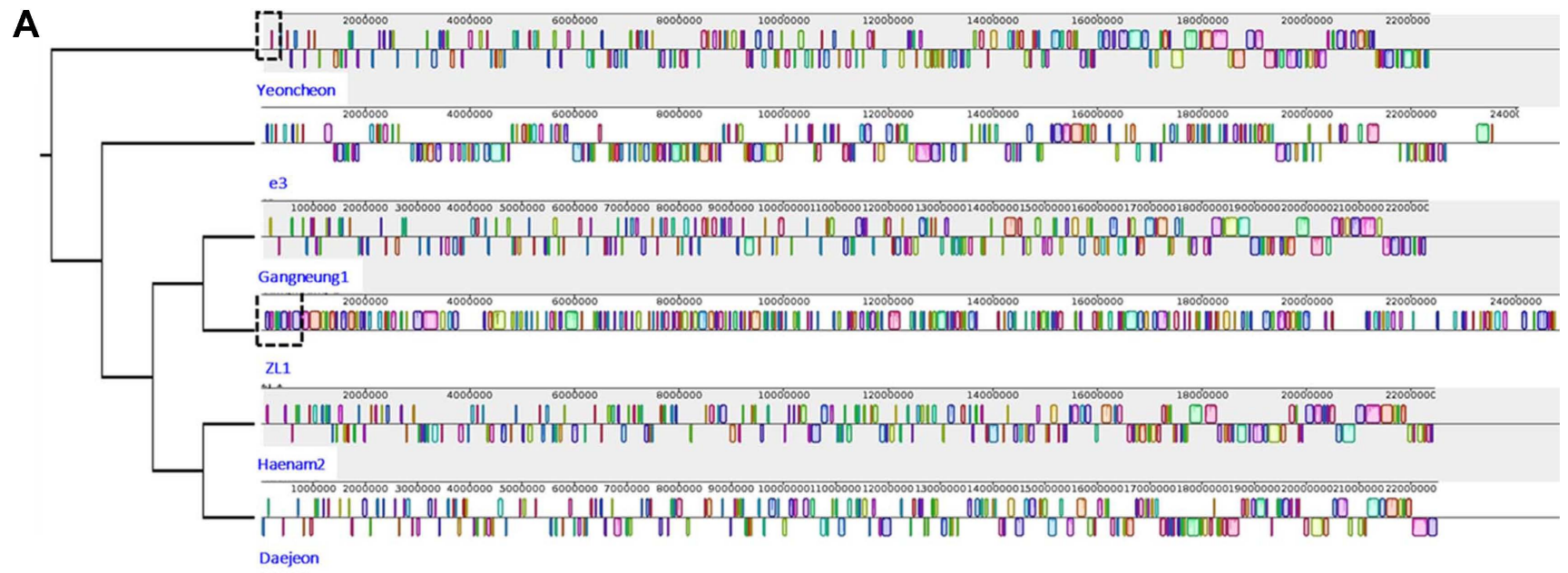

B

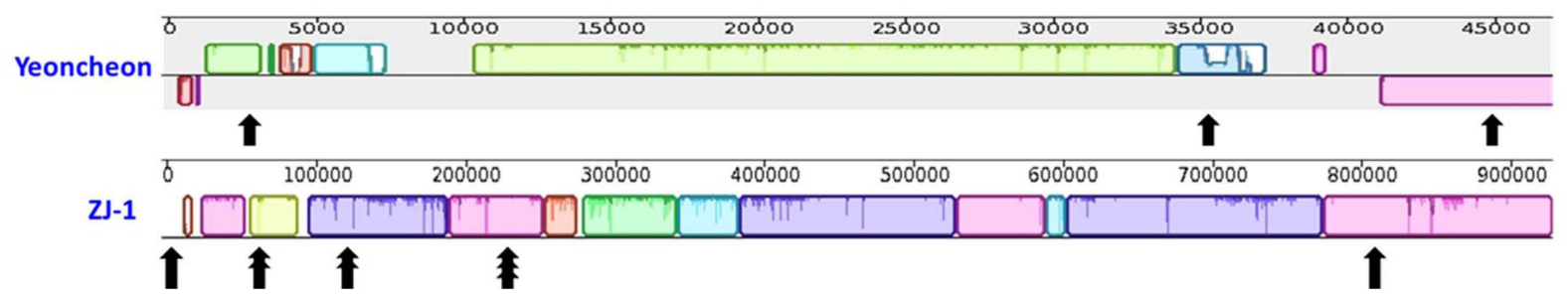

Fig. 1. Alignment of whole genome sequences of Plasmodiophora brassicae. (A) Alignment of five isolates: the dotted rectangles in Yeoncheon and ZL1 indicate the regions where isolate-specific markers were targeted. (B) Identified Yeoncheon- and ZJ1-specific markers regions are highlighted by black arrows.

among these isolates that were used to develop isolatespecific primers (Fig. 1).

Design of isolate-specific primers. Isolate-specific primers were designed using Primer3 software (Koressaar and Remm, 2007; Untergasser et al., 2012). Primer specificity was tested following Robin et al. (2016). A total of 115 primers were designed (Table 2, Supplementary Table 1).

Collection of $\boldsymbol{P}$. brassicae infected isolates. We infected Chinese cabbage variety Bullam-3-ho with 11 previously collected $P$. brassicae isolates: Gangneung (1 and 2), Yeoncheon, Daejeon, Haenam (1 and 2), Seosan, Pyeongchang, Hoengseong, Geumsan, and Goesan (Jo et al.,

Table 2. Forward and reverse primer sequences used to identify Korean Plasmodiophra brassicae isolates

\begin{tabular}{|c|c|c|c|c|c|c|}
\hline \multirow{2}{*}{$\begin{array}{c}\text { Sequence } \\
\text { No. }\end{array}$} & \multirow{2}{*}{$\begin{array}{c}\text { Given primer } \\
\text { name }\end{array}$} & \multirow{2}{*}{ Forward sequence } & \multirow{2}{*}{ Reverse sequence } & \multirow{2}{*}{$\begin{array}{l}\text { Product } \\
\text { Size (bp) }\end{array}$} & \multicolumn{2}{|c|}{ Genomic positions } \\
\hline & & & & & Start & End \\
\hline$>\mathrm{LCB} 455.5$ & Ycheon_9 & ACAGTGCGGGTAGTCTATACG & ACAGTGCGGGTAGTCTATACG & 1317 & 35690 & 34374 \\
\hline$>\mathrm{LCB} 460.5$ & Ycheon_10 & TCGAACCAGAAACCGTGAAC & TTCGGCACATCCCCATACAT & 1589 & 44998 & 43410 \\
\hline$>$ LCB975.5 & Ycheon_14 & GGTATGATTGTACAGGTCGCC & CACTTTCCGGCAAACTACGC & 1459 & 3247 & 1789 \\
\hline$>$ LCB888.2 & $\mathrm{ZJ} 1 \_3$ & TGGACGAGGCTGACAATCTT & CAAAAGCTCACAACGGTCGA & 1073 & 224268 & 223196 \\
\hline$>$ LCB1098.2 & ZJ1_4 & GTCGGCGATCTGGAGAACTA & CACGACGAGCTTCATTCCAG & 1060 & 66622 & 65563 \\
\hline$>\mathrm{LCB} 1098.2$ & ZJ1_5 & CACCAGTATTTCGCGCTTCA & AGGTTTGATCCGCCTGTACA & 1118 & 65497 & 64380 \\
\hline$>$ LCB608.2 & ZJ1_35 & CTCCAACTTGAAAGGCAGAGG & GATGCAACGAACGCTTTGAC & 547 & 761 & 1307 \\
\hline$>$ LCB679.2.1 & ZJ1_40 & TGAATACGAACCGATGCTGC & CGTACACAATGGTTCGGCTG & 517 & 224996 & 224480 \\
\hline$>$ LCB679.2.2 & ZJ1_41 & CGGAGTTGAACGAGACTAGC & GCATACCTAATTGAGCGCGT & 722 & 222677 & 222019 \\
\hline$>$ LCB830.2 & ZJ1_49 & CTTCATCACTAGGCATGCGG & AACGAATCAGTGCATGGACC & 485 & 118258 & 118742 \\
\hline$>$ LCB975.2 & ZJ1 56 & GGTACCGGTTCTTCACGTTC & GAGTGAACCCAGACCTGACA & 1450 & 138164 & 136715 \\
\hline$>\mathrm{LCB} 1188.2$ & ZJ1_61 & TTCACATCACGTTGCACAGG & CCTCCACCGCGTTATCAGTA & 452 & 806998 & 807400 \\
\hline
\end{tabular}


2016; Kim et al., 2016; Lail et al., 2017). Fresh clubroot galls were collected and washed for isolation of $P$. brassicae genomic DNA.

$P$. brassicae DNA isolation. DNA was isolated following the method of Laila et al. (2017). Galls from all isolates were cleaned in running tap water and the outer surface was peeled off. The cleaned galls were then surface-sterilized with $70 \%(v / v)$ ethanol for $60 \mathrm{~s}$. Approximately 100 $\mathrm{mg}$ of gall tissue was collected in a $1.5 \mathrm{ml}$ Eppendorf tube. Individual gall samples were homogenized in $1.5 \mathrm{ml}$ cetrimethyl ammonium bromide (CTAB) $(20 \mathrm{~g} \mathrm{CTAB}, 12.11 \mathrm{~g}$ Tris, $81.8 \mathrm{~g} \mathrm{NaCl}$, and $7.4 \mathrm{~g} \cdot 1^{-1}$ disodium-ethylene diamine tetraacetic acid (EDTA); $\mathrm{pH} 8.0$ ) solution with $30 \mu \mathrm{l}$ proteinase $\mathrm{K}\left(20 \mathrm{mg} \cdot 1^{-1}\right.$, GeneScan) and $30 \mu \mathrm{LNaseI}$ (Sigma, St. Louis, MO, USA). The homogenized galls were then incubated at $60^{\circ} \mathrm{C}$ for $2 \mathrm{~h}$. DNaseI eliminates Brassica rapa host DNA as much as possible (Buhariwalla and Mithen, 1995; Buhariwalla et al., 1995; Manzanares-Dauleux et al., 2001) as it is believed that DNA of P. brassicae become integrated with host DNA during infection process (Bryngelsson et al., 1988). The homogenized suspensions were then centrifuged at $10,000 \times g$ for $5 \mathrm{~min}$. SFG1 Buffer (400 $\mu 1)$ and RNase A ( $4 \mu 1$, Omega Bio-Tek) were mixed with the supernatant in a $1.5 \mathrm{ml}$ tube and vortexed at a maximum speed. The EZNA SP Fungal DNA Miniprep Kit (Omega Bio-Tek, Doraville, GA, USA) was used to extract $P$. brassicae DNA, following the manufacturer's protocol. DNA was stored at $-20^{\circ} \mathrm{C}$ after its quantity and quality were assessed with a Nanodrop ND-1000 spectrophotometer (NanoDrop Technologies, Wilmington, DE, USA).

Extraction of DNA from host control plant. A Japanese cabbage variety (Akimeki) that is resistant to clubroot disease was used as a control to assess the specificity of $P$. brassicae host genomic DNA. Host genomic DNA was extracted with the Qiagen DNeasy Minikit following the manufacturer's instructions (Qiagen, Hilden, Germany).

PCR amplification and agarose gel electrophoresis. The Phusion High-Fidelity DNA PCR kit (New England Biolabs, Inc., Ipswich, MA, USA) was used to amplify genomic DNA of 11 P. brassicae isolates. Each $50 \mu \mathrm{PCR}$ reaction included $1 \mu \mathrm{gDNA}, 2 \mu \mathrm{l}$ of each primer, $0.6 \mu \mathrm{l}$ Phusion DNA Polymerase, $10 \mu$ Phusion HF Buffer, $4 \mu \mathrm{L}$ dNTPs, and $29.4 \mu 1$ sterile distilled water (see Table 2 for primer sequences). Reactions were pre-incubated for $5 \mathrm{~min}$ at $95^{\circ} \mathrm{C}$ followed by 35 cycles of amplification at $95^{\circ} \mathrm{C}$ for $30 \mathrm{~s}, 58^{\circ} \mathrm{C}$ for $30 \mathrm{~s}$ and $72^{\circ} \mathrm{C}$ for $45 \mathrm{~s}$ in an Eppendorf thermal cycler (Eppendorf AG, Hamburg, Germany). The melting of the mixture was carried out at $72^{\circ} \mathrm{C}$ for $5 \mathrm{~min}$. PCR products were visualized on a $1.2 \%$ agarose gel with $1 \times$ TBE buffer.

Isolate-specific marker selection. Race-specific markers were selected based on the presence and absence of amplified bands. When a particular primer pair amplified only one isolate and host DNA, the amplified region was considered an isolate-specific marker.

\section{Results and Discussion}

Sequence comparison. By comparing genomic DNA sequences, we have found several regions that vary among P. brassicae isolates. There $\mathrm{e} 3$ and $\mathrm{ZJ}-1$ isolates had 59.2\% and $59.0 \%$ GC content, respectively. Notable variation in $\%$ GC content was also evident in four Korean $P$. brassicae isolates, ranging from 56.0-59.0 (Fig. 1). We used the e3
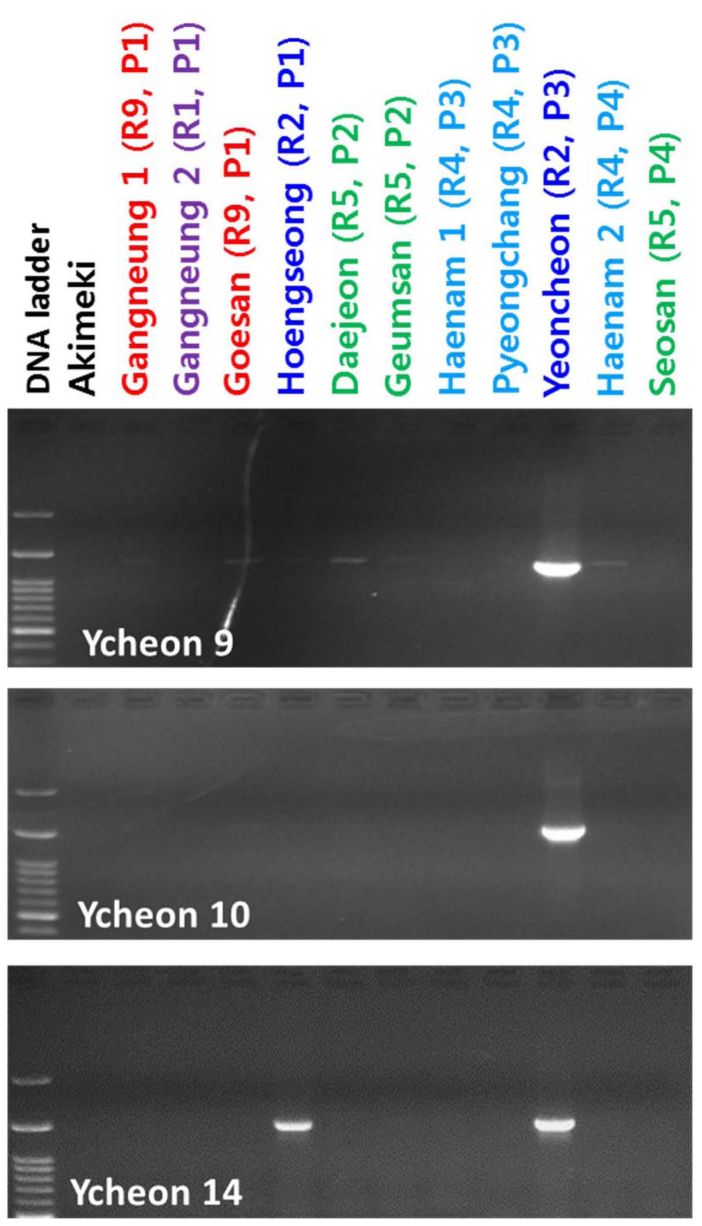

Fig. 2. Three markers specific to the Yeocheon (Ycheon 9 and Ycheon 10), Yeocheon and Hoengseong (Ycheon14) isolates of race 2. Akimeki is a control host. $\mathrm{R}$, race; $\mathrm{P}$, pathotype. 
isolate as a reference genome for the purpose of genome comparisons.

Yeoncheon-isolate specific marker. Out of 117 designed markers, 20 primers were e3-specific, 61 primers were ZJ1specific, two primers were Daejeon-specific, 17 primers were Yeoncheon-specific, six primers were Haenam2-specific, and 11 primers were Gangneung1-specific. Only 12 markers amplified genomic DNA of either a single isolate or two isolates of the same race. The remaining 107 marker sets were non-specific (Supplementary Fig. 1). Two Yeoncheon-specific primers, Ycheon9 and Ycheon10, produced only a single amplicon (Fig. 2), indicating that these sequences characterized amplified region (SCAR) markers might enable specific detection of the Yeoncheon isolate. The primer pair Ycheon 14 amplified the targeted region in both the Yeoncheon and Hoengseong isolates (Fig. 2). Since both of these isolates belong to race 2, this marker may be broadly useful in detecting race $2 P$. brassicae isolates.

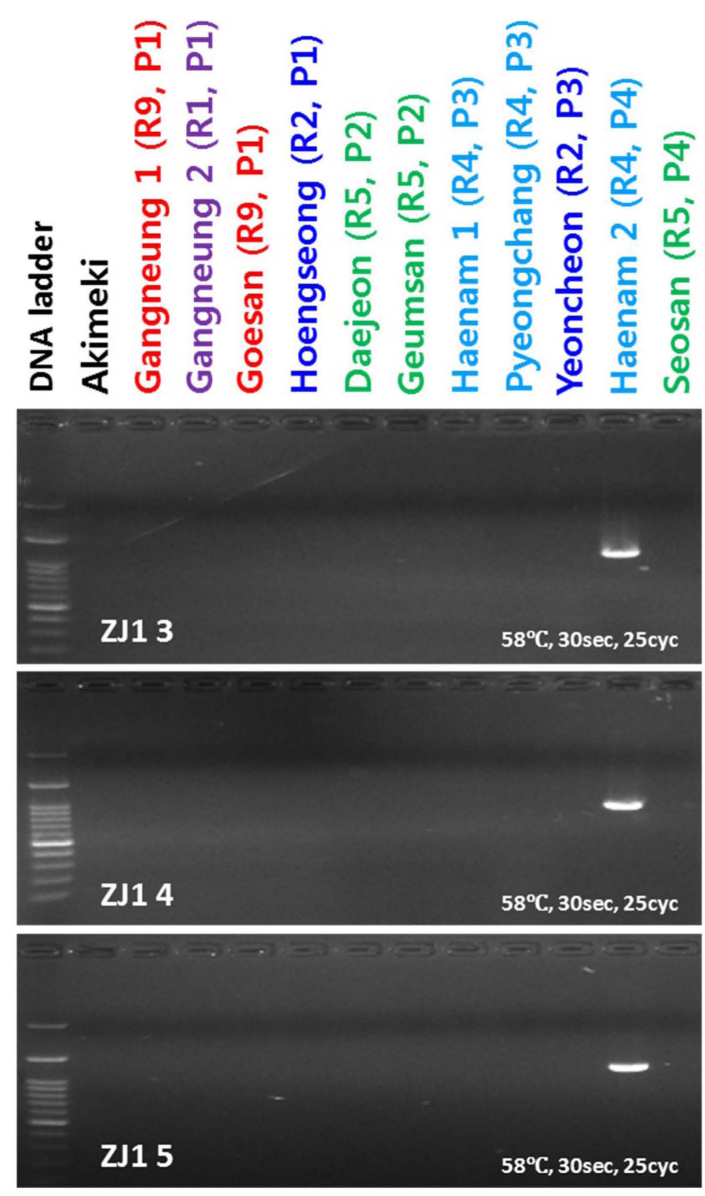

Fig. 3. Three markers showing specificity to the Haenam 2 isolate of race 4 and pathotype 4 . Akimeki, a Japanese Chinese cabbage cultivar, was a control host. $\mathrm{R}$, race; $\mathrm{P}$, pathotype.
The difference in isolate specificity of markers Ycheon9 and Ycheon 10 within race 2 might be due to sequence variation between the isolates Yeoncheon and Hoengseong.

Haenam2-isolate specific markers. Three primer pairs that were designed based on the genomic sequence of the Chinese isolate ZJI (ZJI 3, ZJI 4 and ZJI 5) produced a single amplicon from the Haenam 2 isolate (Fig. 3). These three SCAR markers failed to amplify the target region in the other 10 isolates and the control host plant (Fig. 3). It is possible that these markers also amplify the Chinese $P$. brassicae isolate $\mathrm{ZJI}$, but we did not test this possibility.

Hoengseong-isolate specific markers. Four primer pairs (ZJI 35, ZJI 40, ZJI 41 and ZJI 49) amplified the target region in the Hoengseong isolate only (Fig. 4), indicating that these markers can specifically detect this isolate. Amplification of the Hoengseong isolate with ZJI-specific SCAR markers indicates that the specific primer sequence used is absent in the other $P$. brassicae isolates examined in this study.

Pyeongchang-isolate specific markers. Two other markers (ZJ1 56 and ZJ1 61) amplified the target region in the Pyeongchang-isolate only (Fig. 5). The amplicons were of expected size. These two SCAR markers can be utilized in identifying the Korean $P$. brassicae isolate Pyeongchang. This result further indicated that ZJ1 isolate has genome similarity with only Pyeongchang-isolate at the primer binding site.

Race- and isolate-specific markers and their potential applications. In this study, we developed 12 SCAR markers that identify particular Korean isolates of the clubroot pathogen $P$. brassicae. Eleven of these markers were specific to four single isolates. Importantly, two Yeoncheon isolate-specific markers perfectly amplified only Yeoncheon isolate of Korea. These markers have the potential to specifically identify Yeoncheon-like isolates from Korean fields. Similarly, the other nine SCAR markers were specific to the Haenam2, Hoengseong, and Pyeongchang isolates. Because three Haenam2-specific markers, four Hoengseong-specific markers, and two Pyeongchang-specific markers were designed based on the genome sequence of the Chinese isolate ZJ1, we predict that these markers may also amplify this Chinese isolate, but we did not test this possibility. We therefore recommended that these markers be tested on all $P$. brassicae isolates worldwide to further test their specificity and potentially establish them as universal markers. One of the pre-existing limitation at the 


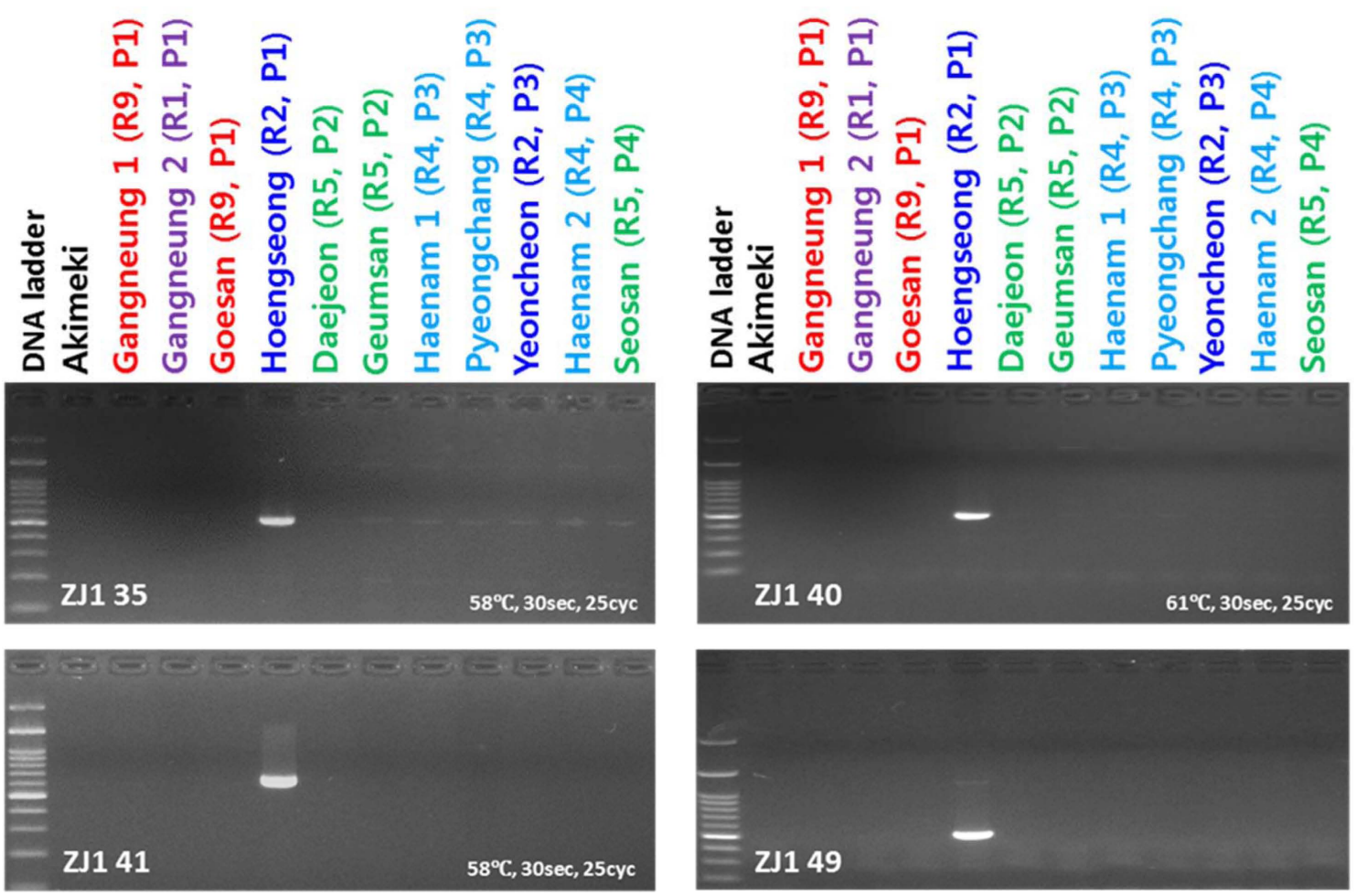

Fig. 4. Four markers showing specificity to the Hoengseong isolate of race 2 and pathotype 1. Akimeki, a Japanese Chinese cabbage cultivar, was a control host. R, race; P, pathotype.

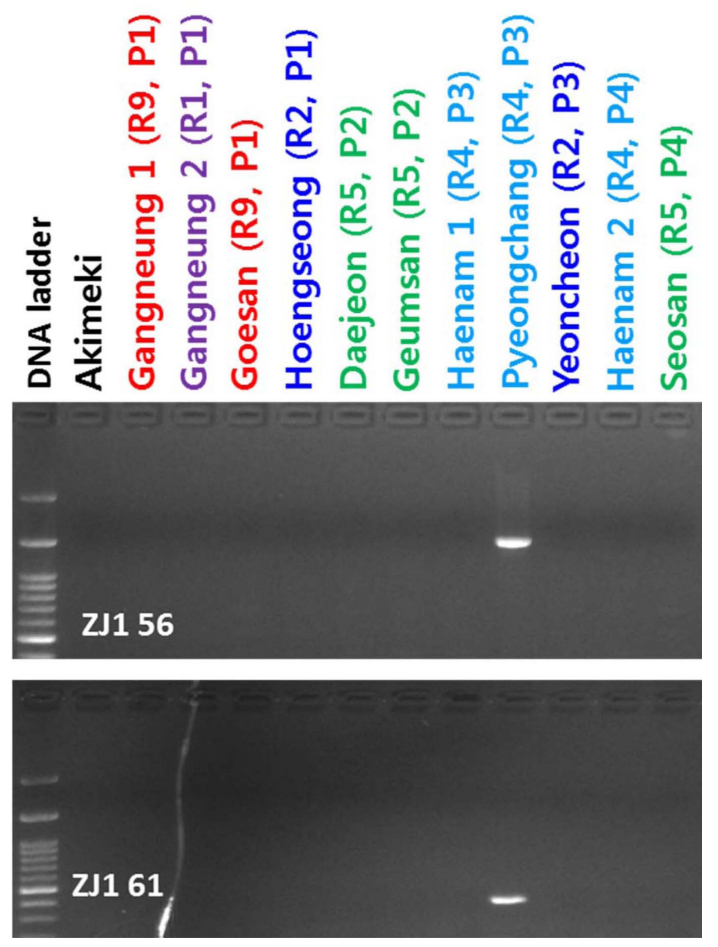

Fig. 5. Four markers showing specificity to the Pyeongchang isolate of race 4 and pathotype 3. Akimeki, a Japanese Chinese cabbage cultivar, was a control host. $\mathrm{R}$, race; $\mathrm{P}$, pathotype. commencement of this study was lack of any race-specific and isolate-specific markers that can detect a particular $P$. brassicae isolate. The newly developed marker can efficiently detect four Korean $P$. brassicae and possibly one Chinese isolate based on genomic DNA sequence variation. Efforts are needed to develop markers to enable detect other Korean P. brassicae isolates.

\section{Author contributions}

I-SN, J-IP and SKN conceived and designed the study. SKN conducted the in silico analysis. RL and JY prepared fungal spores. RL isolated $P$. brasicae DNA. JY and HTK conducted PCR amplification. AHKR wrote the manuscript. AHKR, SKN and JY created the tables and figures. All authors read and approved the final draft of the manuscript.

\section{Acknowledgments}

The authors thank Dr. Gyung Ja Choi, Center for Ecofriendly New Materials, Korea Research Institute of Chemical Technology, Daejeon 34114, Korea for providing $P$. brassicae isolates. This study was supported by the Center 
for Horticultural Seed Development (Golden Seed Project No. 213007-05-2-WT611) of the Ministry of Agriculture, Food and Rural Affairs in the Republic of Korea (MAFRA).

\section{Conflict of interest}

No conflicts of interest exist.

\section{References}

Bryngelsson, T., Gustafsson, M., Gréen, B. and Lind, C. 1988. Uptake of host DNA by the parasitic fungus Plasmodiophora brassicae. Physiol. Mol. Plant Pathol. 33:163-171.

Buczacki, S. T., Toxopeus, H., Mattusch, P., Johnston, T. D., Dixon, G. R. and Hobolth, L. A. 1975. Study of physiologic specialization in Plasmodiophora brassicae: Proposals for attempted rationalization through an international approach. Trans. Br. Mycol. Soc. 65:295-303.

Buhariwalla, H. and Mithen, R. 1995. Cloning of a Brassica repetitive DNA element from resting spores of Plasmodiophora brassicae. Physiol. Mol. Plant Pathol. 47:95-101.

Buhariwalla, H., Greaves, S., Magrath, R. and Mithen, R. 1995. Development of specific PCR primers for the amplification of polymorphic DNA from the obligate root pathogen Plasmodiophora brassicae. Physiol. Mol. Plant Pathol. 47:83-94.

Darling, A. E., Mau, B. and Perna, N. T. 2010. progressiveMauve: multiple genome alignment with gene gain, loss and rearrangement. PloS One 5:e11147.

Dixon, G. R. 2009. The occurrence and economic impact of Plasmodiophora brassicae and clubroot disease. J. Plant Growth Regul. 28:194-202.

Faggian, R. and Strelkov, S. E. 2009. Detection and measurement of Plasmodiophora brassicae. J. Plant Growth Regul. 28:282-288.

Hatakeyama, K., Fujimura, M., Ishida, M. and Suzuki, T. 2004. New classification method for Plasmodiophora brassicae field isolates in Japan based on resistance of $F_{1}$ cultivars of Chinese cabbage (Brassica rapa L.) to clubroot. Breed. Sci. 54:197-201.

Ito, S., Maehara, T., Tanaka, S., Kameyaiwaki, M., Yano, S. and Kishi, F. 1997. Cloning of a single-copy DNA sequence unique to Plasmodiophora brassicae. Physiol. Mol. Plant Pathol. 50:289-300.

Ito, S., Maehara, T., Maruno, E., Tanaka, S., Kameya-Iwaki, M. and Kishi, F. 2008. Development of a PCR-based assay for the detection of Plasmodiophora brassicae in soil. J. Phytopathol. 147:83-88.

Jo, E., Jang, K., Choi, Y., Ahn, K. and Choi, G. 2016. Resistance of cabbage plants to isolates of Plasmodiophora brassicae. Korean J. Hortic. Sci. Technol. 34:442-452.

Jo, S. J., Shim, S. A., Jang, K. S., Choi, Y. H., Kim, J. C. and Choi, G. J. 2011. Resistance of cultivars of Chinese cabbage to Plasmodiophora brassicae isolates of several races col- lected in Korea. Korean J. Hortic. Sci. Technol. 29:610-616.

Karling, J. S. 1968. The Plasmodiophorales. 2nd ed, Hafner Publishing Company, New York, USA. 256 pp.

Kearse, M., Moir, R., Wilson, A., Stones-Havas, S., Cheung, M., Sturrock, S., Buxton, S., Cooper, A., Markowitz, S., Duran, C., Thierer, T., Ashton, B., Mentjies, P. and Drummond, A. 2012. Geneious Basic: an integrated and extendable desktop software platform for the organization and analysis of sequence data. Bioinformatics 28:1647-1649.

Koressaar, T. and Remm, M. 2007. Enhancements and modifications of primer design program Primer3. Bioinformatics 23:1289-1291.

Kim, H., Jo, E. J., Choi, Y. H., Jang, K. S. and Choi, G. J. 2016. Pathotype classification of Plasmodiophora brassicae isolates using clubroot-resistant cultivars of Chinese cabbage. Plant Pathol. J. 32:423-430.

Kim, W. G., Moon, M. H., Kim, J. H., Choi, H. W. and Hong, S. K. 2009. Occurrence of clubroot on pak-choi caused by Plasmodiophora brassicae. Mycobiology 37:69-71.

Kuginuki, Y., Yoshikawa, H. and Hirai, M. 1999. Variation in virulence of Plasmodiophora brassicae in Japan tested with club root resistant cultivars of Chinese cabbage (Brassica rapa L. ssp. pekinensis). Eur. J. Plant Pathol. 105:327-332.

Laila, R. 2018. Molecular investigations towards clubroot resistance and expression of wax biosynthesis genes in Brassicaceae family. $\mathrm{Ph}$. D. thesis. Sunchon National University, Sunchon, Korea.

Laila, R., Robin, A. H., Yang, K., Choi, G. J., Park, J. I. and Nou, I. S. 2017. Detection of ribosomal DNA sequence polymorphisms in the protist Plasmodiophora brassicae for the identification of geographical isolates. Int. J. Mol. Sci. 18:84.

Li, Y., Yuan, Y., Zhao, Y., Wei, X., Yao, Q., Jiang, W., Wang, Z., Yang, S., Zhang, X. and Tian, B. 2017. Pathogen identification of clubroot disease in Chinese cabbage from Yuanyang county, Henan province. Mol. Plant Breed. 8:45-51.

Li, Z., Niu, Y. Z., Wu, Y. C. and Guo, S. X. 2013. Research advances in clubroot disease. Southwest China J. Agri. Sci. 26:1733-1737 (in Chinese).

Manzanares-Dauleux, M. J., Divaret, I., Baron, F. and Thomas, G. 2001. Assessment of biological and molecular variability between and within field isolates of Plasmodiophora brassicae. Plant Pathol. 50:165-173.

Nikolaev, S. I., Berney, C., Fahrni, J. F., Bolivar, I., Polet, S., Mylnikov, A. P., Aleshin, V. V., Petrov, N. B. and Pawlowski, J. 2004. The twilight of heliozoa and rise of Rhizaria, an emerging supergroup of amoeboid eukaryotes. Proc. Natl. Acad. Sci. U.S.A. 101:8066-8071.

Robin, A. H., Yi, G. E., Laila, R., Yang, K., Park, J. I., Kim, H. R. and Nou, I. S. 2016. Expression profiling of glucosinolate biosynthetic genes in Brassica oleracea L. var. capitata inbred lines reveals their association with glucosinolate content. Molecules 21:E787.

Schwelm, A., Fogelqvist, J., Knaust, A., Jülke, S., Lilja, T., Bonilla-Rosso, G., Karlsson, M., Shevchenko, A., Dhandapani, 
V., Choi, S. R., Kim, H. G., Park, J. Y., Lim, Y. P., LudwigMüller, J. and Dixelius, C. 2015. The Plasmodiophora brassicae genome reveals insights in its life cycle and ancestry of chitin synthases. Sci. Rep. 5:11153.

Somé, A., Manzanares, M. J., Laurens, F., Baron, F., Thomas, G. and Rouxel, F. 1996. Variation for virulence on Brassica napus L. amongst Plasmodiophora brassicae collections from France and derived single-spore isolates. Plant Pathol. 45:432-439.

Tsushima, S. 2000. Perspective of integrated pest management-a case study: clubroot disease of crucifers. J. Pest. Sci. 25:296299 (in Japanese).

Untergasser, A., Cutcutache, I., Koressaar, T., Ye, J., Faircloth, B. C., Remm, M. and Rozen, S. G. 2012. Primer3-new capabilities and interfaces. Nucleic Acids Res. 40:e115.

Voorrips, R. E. 1995. Plasmodiophora brassicae: aspects of pathogenesis and resistance in Brassica oleracea. Euphytica 83:139-146.
Wallenhammar, A. C. 1996. Prevalence of Plasmodiophora brassicae in a spring oilseed rape growing area in central Sweden and factors influencing soil infestation levels. Plant Pathol. 45:710-719.

Wallenhammar, A. C. and Arwidsson, O. 2001. Detection of Plasmodiophora Brassicae by PCR in naturally infested soils. Eur. J. Plant Pathol. 107:313-321.

Wang, J., Huang, Y., Hu, X. L., Niu, Y. Z., Li, X. L. and Liang, Y. 2008. Study on symptom, yield loss of clubroot and modality of Plasmodiophora brassicae in rape. Chinese J. Oil Crop Sci. 30:112-115 (in Chinese).

Williams, P. H. 1966. A system for determination of races of Plasmodiophora brassicae that infect Cabbage and Rutabaga. Phytopathology 56:624-626.

Yang, P. W., Yang, Q. Z., Wang, Q., Li, J. R. and Zeng, L. 2002. PCR detection of Plasmodiophora brassicae causing cruciferae clubroot. J. Yunnan Agric. Univ. 17:137-139. 